\title{
PENGARUH KECAKAPAN PROFESIONAL, INDEPENDENSI DAN LAMA BEKERJA TERHADAP HASIL PEMERIKSAAN AUDITOR INTERNAL PADA INSPEKTORAT KABUPATEN/KOTA DI PROVINSI SULAWESI UTARA
}

\author{
Sandi Hasudungan Pasaribu \\ Jenny Morasa \\ Steven Tangkuman
}

sandihasudungan@gmail.com

\begin{abstract}
In the area of financial management supervision entrusted by the Government Internal Supervisory Apparatus (APIP) as an internal auditor internal auditor eventually require attention to the quality of the examination done. Many factors affect the quality of audit reports become among other professional qualifications, independence and work experience. Professional qualifications and independence of the auditor is seen with regard to both th equality audit process and the audit results. Experienced auditors have advantages, including in terms of detecting errors, faults accurately understand, and look for the cause of the error.

The purpose of this study was to determine the effect of professional competence, independence, and long working against the results of an internal auditor a the District / City in the province of North Sulawesi.

Data collection methods used by the survey with a questionnaire containing a list of questions that are answered by the respondents selected that the internal auditor inspectorate. Data analysis techniques to test the hypothesis done using simple linear regression analysis and multiple linear regression were processed through SPSS ver 18.0.

Based on the research results simultaneously ( $F$ test) showed that professionals kills variable (X1), Independence (X2), and longer working (X3) significantly affects the results of the internal auditor in thei nspectorate districts / citiesin North Sulawesi. As for theresults of research partially ( $t$ test) showed that the professional competence and independence of the variables significantly influence the results of the internal auditor in the inspectorate districts / cities in North Sulawesi, while for the old variable work does not affect the results of the auditor on the inspectorate district / city in North Sulawesi Province.
\end{abstract}

Keywords: Professional Skills, Independence, length of work, Internal Auditor Examination Results.

\section{PENDAHULUAN}

\subsection{Latar Belakang}

Tuntutan pelaksanaan akuntabilitas sektor publik terhadap terwujudnya goodgovernancedi Indonesia semakin meningkat. Tuntutan ini memang wajar, karenabeberapa penelitian menunjukkan bahwa terjadinya krisis ekonomi di Indonesiaternyata disebabkan oleh buruknya pengelolaan (badgovernance) dan buruknya birokrasi. Akuntabilitas sektor publik berhubungan dengan praktik transparansi danpemberian informasi kepada publik dalam rangka pemenuhan hak publik. Sedangkangoodgovernancemenurut World Bank didefinisikan sebagai suatu penyelenggaraanmanajeman pembangunan yang solid dan bertanggung jawab dan sejalan denganprinsip demokrasi dan pasar yang efisien, penghindaran salah alokasi dana investasi,pencegahan korupsi baik secara politis maupun administratif, menciptakan disiplinanggaran, serta menciptakan kerangka hukum dan politik bagi tumbuhnya aktivitas usaha.

Terdapat tiga aspek utama yang mendukungterciptanya kepemerintahan yang baik (goodgovernance), yaitu pengawasan,pengendalian, dan pemeriksaan. Pengawasan merupakan kegiatan yang dilakukanoleh pihak di luar eksekutif, yaitu masyarakat dan Dewan Perwakilan Rakyat Daerah(DPRD) untuk mengawasi kinerja pemerintahan. Pengendalian (control) adalahmekanisme yang 
dilakukan oleh eksekutif untuk menjamin bahwa sistem dankebijakan manajemen dilaksanakan dengan baik sehingga tujuan organisasi dapattercapai. Sedangkan pemeriksaan (audit) merupakan kegiatan yang dilakukan olehpihak yang memiliki independensi dan memiliki kompetensi professional untukmemeriksa apakah hasil kinerja pemerintah telah sesuai dengan standar yangditetapkan.

Berkaitan dengan peran dan fungsi tersebut, Inspektorat Kabupaten/Kota di Provinsi Sulawesi Utara mempunyai tugas pokok dan fungsi yang dibentuk berdasarkan Peraturan Gubernur Sulawesi Utara Nomor 6 Tahun 2011 tentang Perubahan atasPeraturan Gubernur Sulawesi Utara Nomor 63 Tahun 2008 tentang Uraian Tugas Inspektorat Provinsi Sulawesi Utara adalah membantu Gubernur dalam melakukan pengawasan terhadap pelaksanaan urusan pemerintahan di daerah provinsi, pelaksanaan pembinaan atas penyelenggaraan pemerintah daerah Kabupaten/Kota dan pelaksana urusan pemerintahan di daerah Kabupaten/Kota. Sedangkan fungsi dari Inspektorat yang pertama ; perencanaan program pengawasan, kedua; perumusan kebijakan dan fasilitas pengawasan, ketiga ; pemeriksaan, pengusutan, pengujian, dan penilaian tugas pengawasan, keempat; pemberian dukungan atas penyelenggaraan pemerintahan daerah dibidang pengawasan, kelima; penyelenggaraan urusan administrasi kesekretariatan, keenam ; pelaksanaan tugas lain yang diberikan Gubernur.

Kualitas hasil pemeriksaan yang dilaksanakan oleh aparat inspektorat Kabupaten/Kota (Propinsi Sulawesi Utara, Kota Manado, Inspektorat Kota Bitung, dan Kabupaten Minahasa Selatan) saat ini masih menjadi perhatian masyarakat, karena masih banyaknya temuan audit yang tidak terdeteksi oleh aparat inspektorat sebagai auditor internal, akan tetapi ditemukan oleh auditor eksternal yaitu Badan Pemeriksa Keuangan (BPK). Berdasarkan hasil pemeriksaan terhadap Laporan Keuangan Pemerintah Daerah (LKPD). BPK masih menemukan adanya kegiatan yang merugikan keuangan negara di Provinsi Sulawesi Utara, dan di sejumlah kabupaten/kota lain, bahkan di Kabupaten Minahasa Selatan (Tahun Anggaran 2010 dan Tahun Anggaran 2011) memperoleh penilaian tidak wajar dan disclamer, sedangkan Kota Manado pada Tahun Anggaran 2009, Tahun Anggaran 2010 memperoleh penilaian tidak wajar dan pada Tahun Anggaran 2011 memperoleh penilaian disclamer. Dalam laporan keuangan tersebut ditemukan masih adanya temuan-temuan berupa ketidakpatuhan terhadap peraturan perundang-undangan, kecurangan, ketidakpatuhan dalam pelaporan keuangan dan lemahnya pengendalian intern.Dengan adanya temuan BPK tersebut, berarti kualitas hasil pemeriksaan aparat inspektorat yang ada di Kabupaten/Kota Sulawesi Utara masih kurang baik.

\subsection{PerumusanMasalah}

Berdasarkan uraian latar belakang yang dikemukakan di atas, maka yang menjadimasalah pokok dalam penelitian ini dapat dirumuskan sebagai berikut:

1. Apakah kecakapan profesional berpengaruh terhadap hasil pemeriksaan auditor internal pada Inspektorat Kabupaten/Kota di Provinsi Sulawesi Utara?

2. Apakah independensi berpengaruh terhadap hasil pemeriksaan auditor internal pada Inspektorat Kabupaten/Kota di Provinsi Sulawesi Utara?

3. Apakah lama bekerja berpengaruh terhadap hasil pemeriksaan auditor internal pada Inspektorat Kabupaten/Kota di Provinsi Sulawesi Utara?

4. Apakah secara bersama-sama kecakapan profesional, independensi dan lama bekerja berpengaruh terhadap hasil pemeriksaan auditor internal pada Inspektorat Kabupaten/Kota di Provinsi Sulawesi Utara?

\subsection{Tujuan Penelitian}

Berdasarkan rumusan masalah yang dikemukakan di atas, maka tujuan penelitianini adalah untuk :

1. Mengetahui pengaruh kecakapan profesional terhadap hasil pemeriksaan auditor internal pada Inspektorat Kabupaten/Kota di Provinsi Sulawesi Utara?

2. Mengetahui pengaruh independensi terhadap hasil pemeriksaan auditor internal pada Inspektorat Kabupaten/Kota di Provinsi Sulawesi Utara?

3. Mengetahui pengaruh lama bekerja terhadap hasil pemeriksaan auditor internal pada Inspektorat Kabupaten/Kota di Provinsi Sulawesi Utara? 
4. Mengetahui secara bersama-sama pengaruh kecakapan profesional, independensi dan lama bekerja terhadap hasil pemeriksaan auditor internal pada Inspektorat Kabupaten/Kota di Provinsi Sulawesei Utara?

\subsection{Manfaat Penelitian} adalah:

Apabila tujuan penelitian ini dapat dipenuhi, maka manfaat yang diharapkan daripenelitian ini

1 Bagi Inspektorat, sebagai masukan dalam mendukung pelaksanaan otonomi daerah khususnya peranan Inspektorat dalam meningkatkan kinerjanya sebagai internal auditor/aparat pengawasan pengelolaan keuangan daerah dan dalam rangka mewujudkan goodgovernance, sehingga Inspektorat diharapkan dapat membuat program yang berkontribusi pada peningkatan kualitas, kapabilitas dan kinerjanya.

2 Bagi Akademisi, memberikan kontribusi pengembangan literatur akuntansi sektor publik di Indonesia terutama sistem pengendalian manajemen di sektor publik.

\subsection{Batasan Masalah Penelitian}

Dalam hal melakukan penelitian, peneliti mempunyai keterbatasan, antara lain :

1. Batasan Aspek, penelitian ini dibatasi pada audit internal di lingkup pemerintahan, khususnya pada tugas dan fungsi Inspektorat Kabupaten/Kota di Sulawesi Utara.

2. Batasan Lokasi penelitian, pada lokasi penelitian terbatas di Pemerintah Provinsi Sulawesi Utara, Kota Manado, Kota Bitung, Kabupaten Minahasa Selatan.

\section{KERANGKA TEORITIS}

\subsection{Grand Theory : TeoriPengambilanKeputusan}

Pengertian Pengambilan Keputusan dikemukakan oleh :

a. Ralp C. Davis;

b. Mary Follet;

c. James A.F. Stoner.

Keputusan dapat dijelaskan sebagai hasil pemecahan masalah, selain itu juga harus didasari atas logika dan pertimbangan, penetapan alternatif terbaik, serta harus mendekati tujuan yang telah ditetapkan.Seorang pengambil keputusan haruslah memperhatikan hal-hal seperti; logika, realita,rasional, dan pragmatis.

\subsubsection{Definisi Audit}

Definisi audit menurut PSAK - Tim Sukses UKT Akuntansi 2006 adalah suatu proses sistematik yang bertujuan untuk memperoleh dan mengevaluasi bukti yang dikumpulkan atas pernyataan atau asersi tentang aksi-aksi ekonomi dan kejadian-kejadian dan melihat bagaimana tingkat hubungan antara pernyataan atau asersi dengan kenyataan dan mengkomunikasikan hasilnya kepada yang berkepentingan.

- $\quad$ Tipe - tipe Audit :

a. Audit Eksternal

b. Audit Internal

- Jenis - jenis Auditor

Auditor dapat dibedakan menjadi tiga jenis, yaitu :

1. Auditor Independen atau Akuntan Publik

2. Auditor Intern

3. Auditor Pemerintahan

\subsubsection{Hasil Pemeriksaan Auditor}

Hasil pemeriksaan auditor adalah probabilitas dimana seorang auditormenemukan dan melaporkan tentang adanya suatu pelanggaran dalam sistemakuntansi kliennya. Deis dan Giroux (1992) dalam Alim $d k k$, (2007:14) dalam penelitiannya terdapat empat hal dianggap mempunyai hubungan dengan kualitas hasil pemeriksaan yaitu : 
1. Lama waktu auditor telah melakukan pemeriksaan terhadap suatu perusahaan (tenure), semakin lama seorang auditor telah melakukan audit pada klien yang sama maka kualitas audit yang dihasilkan akan semakin rendah.

2. Jumlah klien, semakin banyak jumlah klien maka kualitas audit akan semakin baik karena auditor dengan jumlah klien yang banyak akan berusaha menjaga reputasinya.

3. Kesehatan keuangan klien, semakin sehat kondisi keuangan klien maka aka nada kecenderungan klien tersebut untuk menekan auditor agar tidak mengikuti standar, dan ;

4. Review oleh pihak ketiga, kualtias audit akan meningkat jika auditor tersebut mengetahui bahwa hasil pekerjaannya akan direview oleh pihak ketiga.

\subsubsection{Kecakapan Profesional}

Dalam Peraturan Menteri Negara Pendayagunaan Aparatur Negara No. PER/05/M.PAN/03/2008 tanggal 31 maret 2008 tentang standar audit, auditor harus menggunakan keahlian profesionalnya dengan cermat dan seksama (dueprofessionalcare) dan secara hati-hati (prudent) dalam setiap penugasan. Sedangkan Peraturan Badan Pemeriksa Keuangan Republik Indonesia No. 01 Tahun 2007 tentang Standar Pemeriksaan Keuangan Negara dinyatakan dalam pelaksanaan pemeriksa serta penyusunan laporan hasil pemeriksaan, pemeriksa wajib menggunakan kemahiran profesionalnya secara cermat dan seksama.

\subsubsection{Independensi}

Menurut Messieretal(2005) dalam Efendy (2010), independensi merupakan suatu istilah yang sering digunakan oleh profesi auditor. Independensi menghindarkan hubungan yang mungkin mengganggu obyektivitas auditor. Dalam lampiran 2 SPKN disebutkan bahwa: "Gangguan pribadi yang disebabkan oleh suatu hubungan dan pandangan pribadi mungkin mengakibatkan pemeriksa membatasi lingkup pertanyaan dan pengungkapan atau melemahkan temuan dalam segala bentuknya.

\subsubsection{Lama Bekerja}

Siagian (2008:20) menyatakan bahwa masa kerja/lama bekerja menunjukkan berapa lama seseorang bekerja pada masing-masing pekerjaan atau jabatan. Annesadkk (2011:7) menyatakan bahwa masa kerja yang lama akan cenderung membuat seorang pegawai lebih merasa betah dalam suatu organisasi, hal ini disebabkan diantaranya karena telah beradaptasi dengan lingkungannya yang cukup lama sehingga seorang pegawai akan merasa nyaman dengan pekerjaannya. Penyebab lain juga dikarenakan adanya kebijakan dari instansi atau perusahaan mengenai jaminan hidup di hari tua.

\section{KERANGKA KONSEPTUAL}

\subsection{KerangkaKonseptual}

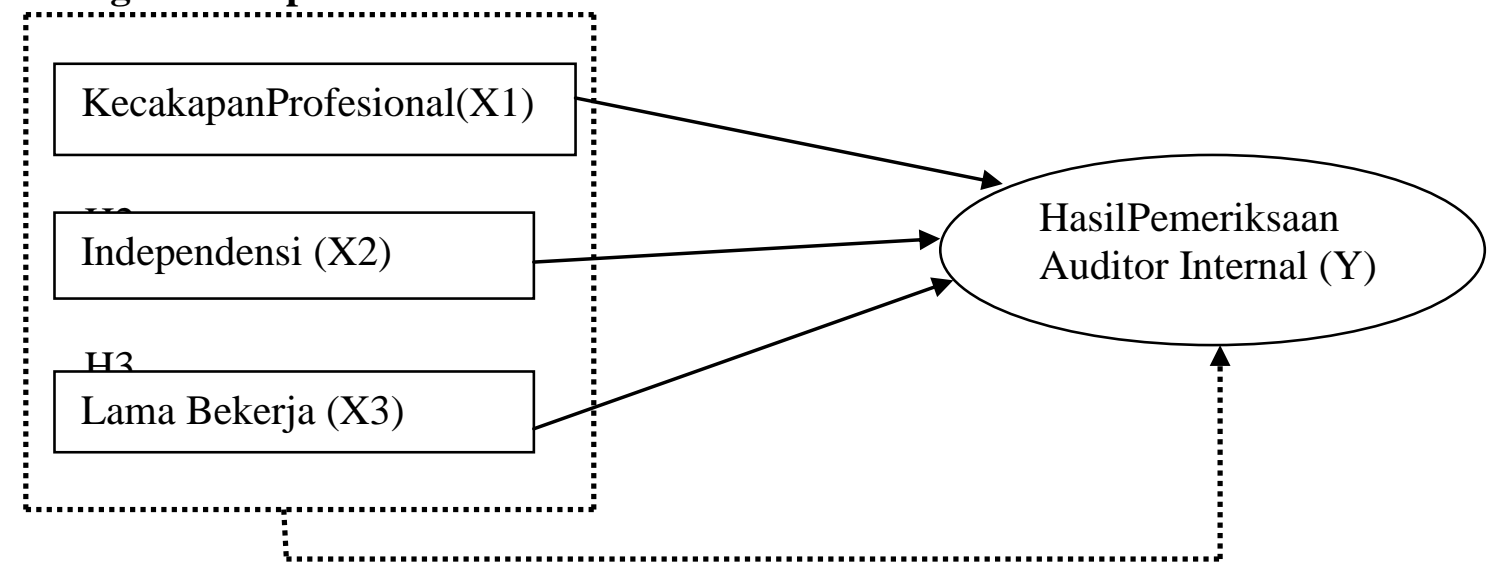

\subsection{Hipotesis}

Gambar 3.1 KerangkaKonseptual

Berdasarkan latar belakang masalah, rumusan masalah, landasan teori, dan kerangka konseptual yang dikemukakan maka dikembangkan hipotesis dengan penjelasan sebagai berikut : 
$\mathrm{H}_{1}$ ： Kecakapan profesional berpengaruh signifikan terhadap hasil pemeriksaan auditor internal pada Inspektorat Kabupaten/Kota di Sulawesi Utara.

$\mathrm{H}_{2}$ : Independensi berpengaruh signifikan terhadap hasil pemeriksaan auditor internal pada Inspektorat Kabupaten/Kota di Provinsi Sulawesi Utara.

$\mathrm{H}_{3}$ : Lama bekerja berpengaruh signifikan terhadap hasil pemeriksaan auditor internal pada Inspektorat Kabupaten/Kota di Provinsi Sulawesi Utara.

\subsection{Model Analisis}

Penelitian ini menggunakan metode induktif atau inferensia berupa metode analisis regresi linear berganda. Dengan menggunakan formula :

Keterangan :

$$
Y=\alpha+\beta_{1} X_{1}+\beta_{2} X_{2}+\beta_{3} X_{3}+e
$$

$\begin{array}{lll}\mathrm{Y} & = & \text { Hasil pemeriksaan auditor internal } \\ \alpha & = & \text { Konstanta } \\ \beta_{1,} \beta_{2,} \beta_{3}, & = & \text { Koefisien regresi } \\ \mathrm{X}_{1} & = & \text { Kecakapan profesional } \\ \mathrm{X}_{2} & = & \text { Independensi } \\ \mathrm{X}_{3} & = & \text { Lama Bekerja } \\ \mathrm{e} & = & \text { error }\end{array}$

\section{METODE PENELITIAN}

\subsection{Populasi dan Sampel}

Objek populasi dari penelitian ini adalah auditor pada Inspektorat Propinsi Sulawesi Utara, Inspektorat Kota Manado, Inspektorat Kota Bitung, dan Inspektorat Kabupaten Minahasa Selatan.

Dalam penelitian ini peneliti mengambil auditor internal yang ada di lingkungan Inspektorat Provinsi Sulawesi Utara, Inspektorat Kota Manado, Inspektorat Kota Bitung, dan Inspektorat Kabupaten Minahasa Selatan. Karena lokasinya yang berdekatan dengan peneliti. Sehingga sampel dalam penelitian ini berjumlah 97 auditor internal.

\subsection{Metode Pengumpulan Data}

Data yang digunakan dalam penelitian ini adalah data primer yang diperoleh dengan metode pengumpulan datanya menggunakan daftar pertanyaan (kuesioner) terstruktur dengan tujuan untuk mengumpulkan informasi dari auditor pada Inspektorat Propinsi Sulawesi Utara, Inspektorat Kota Manado, Inspektorat Kota Bitung, Inspektorat Kabupaten Minahasa Selatan, dan sebagai responden dalam penelitian ini.

\subsection{Klasifikasi Variabel dan Definisi Operasional Variabel}

Dalam penelitian ini, variabel dependen (Y) yang digunakan adalah hasil pemeriksaanauditor internal, sedangkan variabel independennya terdiri dari kecakapan profesional $\left(\mathrm{X}_{1}\right)$, independensi $\left(\mathrm{X}_{2}\right)$, dan lama bekerja $\left(\mathrm{X}_{3}\right)$.

Definisi operasional dan pengukuran untuk variabel-variabel tersebut adalah:

1. Hasil pemeriksaan auditor internal (Y) merupakan probabilitas bahwa auditor akan menemukan danmelaporkan pelanggaran pada sistem akuntansi pemerintah dengan berpedomanpada standar akuntansi dan standar audit yang telah ditetapkan. Indikator :kelemahan pengendalian intern, tanggapan dari auditee, kerahasiaan informasi, pendistribusian laporan hasil pemeriksaan (LHP), dan temuan dan rekomendasi hasil pemeriksaan harus ditindak lanjut oleh pimpinan. Instrumen yang digunakan untuk mengukur hasil pemeriksaan auditor internal ini diadopsi dari penelitian Rizal (2008) dengan beberapamodifikasi berdasarkan SPKN.

2. Kecakapan profesional $\left(\mathrm{X}_{1}\right)$ dalam pemeriksaan merupakan pengetahuan, keahlian, dan pengalaman yang dibutuhkan auditor untuk dapat melakukan audit secara objektif, cermat dan seksama, dengan selalu mengikuti perkembangan mutakhir terhadap aturan-aturan yang berlaku. Indikator :telah mengikuti training akuntansi, audit dan pengalaman dalam melakukan pemeriksaan. Instrumen yang digunakan untuk mengukur kecakapan profesional ini diadopsi dari penelitian Rizal (2008) dengan beberapa modifikasi berdasarkan SPKN. 
3. Independensi $\left(\mathrm{X}_{2}\right)$ adalah pemeriksa tidak memiliki hubungan kerjasama dengan entitas atau program yang diperiksa, pemeriksa dalam melakukan pemeriksaan tidak mempunyai batasan waktu yang tidak wajar, organisasi pemeriksa harus bebas dari hambatan independensi, dan tidak ada campur tangan dari pihak ekstern mengenai penugasan, penunjukan dan promosi pemeriksa. Indikator :pemeriksa tidak memiliki kerja sama dengan yang diperiksa, tidak ada pembatasan waktu yang tidak wajar dalam pemeriksaan, organisasi pemeriksaan bebas dari hambatan independensi, dan tidak ada campur tangan pihak ekstern dalam pemeriksaan. Instrumen yang digunakan untuk mengukur independensi ini diadopsi dari penelitian Rizal (2008) dengan beberapa modifikasi berdasarkan SPKN.

4. Lama bekerja $\left(\mathrm{X}_{3}\right)$ merupakan pengalaman individu yang akan menentukan pertumbuhan dalam pekerjaan dan jabatan serta keterampilan dan pengetahuan seseorang setelah mengerjakan suatu hal. Indikator :banyaknya tugas pemeriksaan yang telah dilakukan, pengalaman kerja dan banyaknya pelatihan yang telah diikutinya. Instrumen yang digunakan untuk mengukur kecakapan profesional ini diadopsi dari penelitian Sukriah $d k k(2009)$ dengan beberapamodifikasi berdasarkan SPKN.

\subsection{Metode Analisis Data}

Sebelum melakukan pengujian dengan regresi linear berganda, terlebih dahulu dilakukan Uji Asumsi Klasik,antara lain :Uji Normalitas, Uji Autokorelasi, Uji Heterokedastisitas, Uji Multikolinearitas, Analisis Regresi Linear Berganda, Koefisien Korelasi (R)\&Determinasi $\left(\mathrm{R}^{2}\right)$ dan Uji Hipotesis

\section{HASIL PENELITIAN DAN PEMBAHASAN}

\subsection{Hasil Analisis}

\section{Uji Asumsi Klasik}

Uji Normalitas

\begin{tabular}{c|c} 
& Tabel 5.1 Test of Normality \\
\hline & Unstandardized Residual \\
\hline df & 87 \\
Kolmogorov-Smirnov & .068 \\
Asymp. Sig. (2-tailed) & $.200^{\mathrm{a}}$ \\
\hline
\end{tabular}

Sumber :Hasil Olah Data SPSS, 2014

Dari Tabel diatas, terlihat bahwa nilai Sig. (2-tailed) dalam One-SampleKolmogorov-Smirnov Test adalah 0,200 ( > 0,05), sehingga H0 diterima. Ini berarti bahwa data yang diuji menyebar normal / terdistribusi normal.

\section{Uji Autokorelasi}

\begin{tabular}{c|c} 
Tabel5.2 Model Summary $^{\mathbf{b}}$ \\
\hline Model & Durbin-Watson \\
\hline 1 & $1.649^{\mathrm{a}}$ \\
\hline Sumber :Hasil Olah Data SPSS, 2014
\end{tabular}

Berdasarkan pada diatas, nilai DW yang dihasilkan adalah sebesar 1,649, maka dapat disimpulkan bahwa data penelitian berada di daerah ragu-ragu.

\section{Uji Multikolinearitas}

\begin{tabular}{l|c|c}
\multicolumn{2}{c}{ Tabel 5.3 Coefficients $^{\mathbf{a}}$} \\
\hline \multicolumn{1}{c}{ Model } & \multicolumn{2}{c}{ Collinearity Statistic } \\
\cline { 2 - 3 } & Tolerance & VIF \\
\hline KecakapanProfesional & .997 & 1.003 \\
Independensi & .993 & 1.007 \\
Lama Bekerja & .994 & 1.006 \\
\hline
\end{tabular}

Sumber :Hasil Olah Data SPSS, 2014

Dengan melihat nilaiVIF pada tabel diatas, setiap variabel independen dibawah 10, yaitu kecakapan professional sebesar 1,003, independensi sebesar 1.007, lama bekerja sebesar 1.006, maka dapat disimpulkan bahwa variabel penelitian bebas efek multikolinearitas. 


\begin{tabular}{l|l}
\multicolumn{2}{c}{ Tabel 5.4 Coefficients $^{\mathbf{a}}$} \\
\hline \multicolumn{1}{c}{ Model } & Sig. \\
\hline $1 \quad$ (Constant) & .090 \\
KecakapanProfesional & .367 \\
Independensi & .854 \\
Lama Bekerja & .428 \\
\hline
\end{tabular}

Sumber :HasilOlah Data SPSS, 2014

Berdasarkan diatas, nilai signifikansi untuk masing-masing variabel independen terhadap nilai absolute residual berada di atas 0,05 , sehingga dapat disimpulkan tidak terdapat gejala heteroskedastisitas pada data penelitian ini.

\section{Analisis Regresi Linear Berganda}

Tabel 5.5 Coefficients ${ }^{\mathrm{a}}$

\begin{tabular}{l|r|r|r}
\hline Model & $\mathrm{B}$ & $\mathrm{t}$ & Sig. \\
\hline $1 \quad$ (Constant) & 10.711 & 2.634 & .011 \\
KecakapanProfesional & .576 & 4.220 & .000 \\
Independensi & .715 & 2.692 & .009 \\
Lama Bekerja & .108 & 1.104 & .275 \\
\hline
\end{tabular}

Sumber :HasilOlah Data SPSS, 2014

Dari Tabel di atas, maka dapat diketahui bahwa model regresi yang diperoleh adalah :

$$
\begin{aligned}
& Y=\alpha+\beta_{1} X_{1}+\beta_{2} X_{2}+\beta_{3} X_{3}+e \\
& Y=10.711+0.576 X_{1}+0.715 X_{2}+0.108 X_{3}
\end{aligned}
$$

\section{Koefisien Korelasi dan Determinasi}

Tabel 5.6 Model Summary

\begin{tabular}{l|c|c}
\hline Model & R Square & Adjusted Square \\
\hline 1 & .289 & .243 \\
\hline
\end{tabular}

Sumber :HasilOlah Data SPSS, 2014

Berdasarkan diatas, dapat dilihat perbandingan hasil dari uji koefisien determinasi, dimana jika dilihat dari nilai adjusted $\mathrm{R}$ squarenya, hasil uji dengan variabel moderasi lebih baik daripada hasil uji tanpa variabel moderasi, hal tersebut dapat kita lihat dari perbandingan nilai adjusted $\mathrm{R}$ square.

Untuk mengetahui seberapa besar pengaruh variabel indepen (kecakapan profesional, independensi, dan lama bekerja) terhadap variabel dependennya (hasil pemeriksaan auditor internal) digunakan Nilai adjusted R2 tanpa variabel moderasi yaitu sebesar 0,243, memiliki arti bahwa 24,3\% perubahan hasil pemeriksaan auditor internal dapat dijelaskan oleh variabel kecakapan profesional, independensi, lama bekerja. Sedangkan sisanya 75,7\% dipengaruhi oleh variabel lain diluar model.

\subsubsection{Uji Hipotesis \\ $\underline{\text { Hasil Uji F }}$}

Tabel 5.7 ANOVA ${ }^{b}$

\begin{tabular}{c|c|c|c|c}
\hline Model & Sum of Square & Df & F & Sig. \\
\hline $1 \quad$ Regression & 88.281 & 3 & 6.240 & $.001^{\mathrm{a}}$ \\
Residual & 216.939 & 83 & & \\
Total & 305.220 & 86 & & \\
\hline
\end{tabular}

Sumber :Hasil Olah Data SPSS, 2014 
Tabel 5.8 Coefficients ${ }^{a}$

\begin{tabular}{l|r|r|r}
\hline Model & $\mathrm{B}$ & $\mathrm{t}$ & Sig. \\
\hline $1 \quad$ Constant) & 10.711 & 2.634 & .011 \\
Kecakapan Profesional & .576 & 4.220 & .000 \\
Independensi & .715 & 2.692 & .009 \\
Lama Bekerja & .108 & 1.104 & .275 \\
\hline
\end{tabular}

Sumber :Hasil Olah Data SPSS, 2014

\subsection{Pembahasan}

\subsubsection{Pengaruh Kecakapan Profesional terhadap Hasil Pemeriksaan Auditor Internal}

Hipotesis pertama menyatakan bahwa kecakapan profesional berpengaruh signifikan terhadap hasil pemeriksaan auditor internal. Hasil pengujian statistik menunjukkan nilai signifikansi variabel kompetensi $=0.000<0,05$, maka maka dapat dinyatakan bahwa Ho ditolak dan Ha diterima. secara parsial kecakapan profesional berpengaruh signifikan terhadap hasil pemeriksaan auditor internal.

Hasil penelitian ini mendukung hipotesis pertama bahwa kecakapan profesional berpengaruh terhadap kualitas hasil pemeriksaan. Hal ini berarti kualitas hasil pemeriksaan dapat dicapai jika auditor memiliki kecakapan profesional yang baik. Kecakapan profesional tersebut terdiri dari dua dimensi yaitu pengalaman dan pengetahuan. Auditor sebagai ujung tombak pelaksanaan tugas audit memang harus senantiasa meningkatkan pengetahuan yang telah dimiliki, agar penerapan pengetahuan dapat maksimal dalam praktiknya. Penerapan pengetahuan yang maksimal tentunya akan sejalan dengan semakin bertambahnya pengalaman yang dimiliki. Sesuai dengan standar umum bahwa auditor disyaratkan memiliki pengalaman kerja yang cukup dalam profesi yang ditekuninya, serta dituntut untuk memenuhi kualifikasi teknis dan berpengalaman dalam bidang industri yang digeluti kliennya.

\subsubsection{Pengaruh Independensi terhadap Hasil Pemeriksaan Auditor Internal}

Hasil statistic pada analisis regresi linier berganda, dapat dilihat bahwa nilai signifikansi variabel independensi (X2) 0,009> 0,05 maka dapat dinyatakan bahwa Ho ditolak dan Ha diterima, Dengan demikian independensi (variabel X2) berpengaruh signifikan terhadap hasil pemeriksaan auditor internal (variabel Y).

Hasil pengujian hipotesis ini tidak sejalan dengan pendapat elfarini (2007), Sukriah $d k k$ (2009), Dan Efendy (2010) yang menyimpulkan bahwa independensi berpengaruh tidak signifikan terhadap kualitas hasil pemeriksaan, sehingga independensi yang dimiliki aparat inspektorat tidak menjamin apakah yang bersangkutan akan melakukan audit secara berkualitas. Memang tidak mudah menjaga tingkat independensi agar tetap sesuai dengan jalur yang seharusnya. Diduga karena independensi aparat inspektorat masih terpengaruh dengan penentu kebijakan yang dapat mengintervensi hasil pemeriksaan, disamping itu kerjasama dengan klien yang terlalu lama bisa menimbulkan kerawanan atas independensi yang dimiliki auditor karena auditor dan auditee sama-sama di lingkungan pegawai yang sama sehingga menimbulkan hubungan interpersonal baik hubungan kekerabatan atau relasi kepentingan lainnya dan seringnya kepala daerah melakukan mutasi antar satuan kerja perangkat daerah. Belum lagi jika auditor melakukan pemeriksaan, mereka mendapatkan berbagai fasilitas yang disediakan auditee selama penugasan audit yang bisa saja mempengaruhi independensi dalam pemeriksaan, meskipun aparat acap kali mendapat fasilitas dari auditee, namun aparat tetap menganggap bahwa audit yang baik tetap harus dilaksanakan.

\subsubsection{Pengaruh Lama Bekerja terhadap Hasil PemeriksaanAuditor Internal}

Dari hasil perhitungan pada tabel 5.28 didapat nilai t hitung antara lama bekerja terhadap hasil pemeriksaan auditor sebesar 1.104 dengan tingkat signifikansi sebesar 0,275. Dengan nilai signifikasinya yang lebih besar dari 0,05 maka variabel lama bekerja tidak berpengaruh terhadap hasil pemeriksaan auditor.

Hal ini menunjukkan beberapa faktor yang menjadi penyebab terjadinya lama bekerja tidak berpengaruh terhadap hasil pemeriksaan auditor internal pada inspektorat kabupaten/kota di Sulawesi Utara karena kurangnya pelatihan/bimtek yang dilaksanakan oleh BPKP yang mana pelaksanaannya 
cuma 2 kali salam setahun sehingga minimnya pengetahuan auditor internal mengenai auditing dan masih sedikit latar belakang pendidikan auditor mengenai akuntansi dan audit, dan faktor lain adanya mutasi aparat auditor internal yang berpengalaman yang sudah mengikuti berbagai pelatihan terlebih dalam mengenai audit dan akuntansi sehingga dingantikan dengan auditor yang tidak memiliki cukup pengalaman maka akan menyebabkan kualitas audit terhadap hasil pemeriksaan laporan keuangan rendah. Sesuai dengan tabel 5.5 (Komposisi Responden Lama Bekerja) menunjukkan auditor yang lama bekerja diatas 10 tahun masih sangat sedikit yaitu cuma 6 orang auditor, sedangkan lama bekerja auditor 4-6 tahun sangat besar yaitu 45 orang auditor, sehingga dapat disimpulkan bahwa auditor yang belum berpengalaman atau yang masih baru menjabat sebagai auditor internal pada inspektorat disebabkan karena adanya factor politik dan hubungan keluarga sehingga menyebabkan penempatan sebagai aparat inspektorat di kabupaten/kota di Provinsi Sulawesi Utara tidak sesuai dengan keahlian/kompetensinya.

\section{KESIMPULAN DAN SARAN}

\section{Kesimpulan}

Berdasarkan hasil pembahasan, maka dapat diambil kesimpulan sebagai berikut :

1. Kecakapan profesional berpengaruh terhadap hasil pemeriksaan auditor internal, sehingga semakin baik tingkat kecakapan profesional, seperti penguasaan standar akuntansi dan auditing, wawasan tentang pemerintahan dan pengalaman seperti yang didapat melalui training akuntansi dan trainingauditing maka akan semakin baik hasil pemeriksaan yang dilakukannya.

2. Independensi berpengaruh terhadap hasil pemeriksaan auditor internal, sehingga semakin meningkatnya independensi seorang auditor akan meningkatkan hasil pemeriksaan auditor internal, artinya kualitas audit dapat dicapai jika auditor memiliki independensi yang baik.

3. Lama bekerja tidak berpengaruh terhadap hasil pemeriksaan auditor, disebabkan karenan kurangnya pelatihan/bimtek yang di laksanakan untuk menunjang pengetahuan auditor dalam auditng dan akuntansi yang mana cuma 2 kali dalam setahun dilaksanakan, serta adanya mutasi aparat inspektorat kabupaten/kota di provinsi Sulawesi Utara yang sudah berpengalaman dan yang sudah mengikuti berbagai pelatihan dalam hal auditing dan akuntansi tergantikan dengan yang tidak memiliki cukup pengalaman, sehingga kualitas audit terhadap pemeriksaan laporan keuangan menjadi rendah.

\section{Saran}

Setelah melakukan dan melihat hasil dari penelitian ini, maka penulis dapat memberikan beberapa saran. Adapun saran-saran tersebut adalah sebagai berikut :

1. Penempatan pegawai di lingkup Inspektorat Kabupaten/Kota di Sulawesi Utara sebaiknya berdasarkan fungsi dan keahlian yang dimiliki.

2. Peneliti menganjurkan agar penentu kebijakan perlu terus menjagadan meningkatkan keahlian aparat inspektorat melalui pemberian pelatihan-pelatihan/Bimtek sertakesempatan untuk mengikuti kursus-kursus atau peningkatan pendidikan profesi.

\section{DAFTAR PUSTAKA}

Agoes, Sukrisno. 2004. Auditing (Pemeriksaan Akuntan)Oleh Kantor Akuntan Publik. Jilid 1, Jakarta: Fakultas Ekonomi Universitas Indonesia.

Alim, M.N., T. Hapsari, dan L. Purwanti. 2007. Pengaruh Kompetensi dan Independensi terhadap Kualitas Audit dengan Etika Auditor sebagai Variabel Moderasi. Simposium Nasional Akuntansi X. Makassar.

Direktorat Jenderal Keuangan Daerah (DJKD), 2013. 300 Kepala Daerah Terjerat Kasus Korupsi, diakses 25 April 2014, http://djkd.kemendagri.go.id/?jenis=news \& $p=$ detail berita\&id=861

Effendi, Muh. Taufiq,2010. Pengaruh Kompetensi, Independensi, dan Motivasi Terhadap Kualitas Audit Aparat Inspektorat Dalam Pengawasan Keuangan Daerah (Studi Empiris pada Pemerintah Kota Gorontalo).(Tesis tidak dipublikasikan).

Konsorsium Organisasi Profesi Audit Internal. 2004. Standar Profesi Audit Internal. Ditetapkan tanggal 12 Mei 2004. Berlaku mulai 1 Januari 2005. Jakarta.www.internalauditing.or.id 
Kuncoro,2003. Metode Riset Untuk Bisnis dan Ekonomi : Bagaimana Meneliti dan Menulis Tesis?, Erlangga, Jakarta.

Peraturan Badan Pemeriksa Keuangan Republik Indonesia No. 01 Tahun 2007 tentang Standar Pemeriksaan Keuangan Negara. Badan Pemeriksaan Keuangan RI tahun 2007.

Peraturan Menteri Dalam Negeri No. 64 Tahun 2007, tentang Pedoman Teknis Organisasi dan Tata kerja Inspektorat Provinsi dan Kabupaten/Kota. Jakarta. 2007.

Jakarta. 2006.

Peraturan Menteri Negara Pendayagunaan Aparatur Negara nomor PER/05/M.PAN/03/2008. Standar Audit Aparat Pengawasan Intern Pemerintah. Jakarta.

Peraturan Gubernur Sulawesi Utara Nomor 6 Tahun 2011. Tentang Uraian Tugas Inspektorat Provinsi Sulawesi Utara.

Rahman, Ahmad Taufik. 2009.Jurnal. Persepsi Auditor Mengenai Pengaruh Kompetensi, Independensi dan Due Profesional Care Terhadap Kualitas Audit. Fakultas Ekonomi Universitas Soedirman.

Siagian, P. Sondang. 2004. Audit Manajemen. Penerbit Bumi Aksara.

Tim Peneliti UNSRAT, Pemda SULUT, dan staf Bank Dunia, 2011. Analisis Keuangan Publik Provinsi Sulawesi Utara 2011, Pengelolaan Keuangan Daerah dan Pembangunan di Bumi Nyiur Melambai. Kantor Bank Dunia Jakarta.

Yayasan Pendidikan Internal Auditor. 2003. Audit TI : Siapa yang Diuntungkan? E-Bizz Asia. Vol. II No. 17. Mei-Juni. 